\title{
Prenatal ultrasonographic diagnosis of axillary cystic hygroma
}

\author{
Narayan Bikram Thapa, Ganesh Dangal* \\ Department of Radiology and Ob/Gyn * Kathmandu Model Hospital, Nepal
}

\begin{abstract}
Cystic hygromas are characterized by single or multiple cysts within soft tissue. They may occur in isolation or may be associated with other congenital malformations and can lead to obstructed labour or neonatal asphyxia. Ultrasonography in the prenatal period can be carried out to diagnose congenital cystic hygromas.
\end{abstract}

Keywords: ultrasonography, cystic hygroma

\section{Introduction}

Cystic hygromas are anomalies of the lymphatic system characterized by single or multiple cysts within soft tissue. ${ }^{1}$ The prenatal diagnosis of cystic hygroma by ultrasound is well documented in literature. ${ }^{2}$ Approximately $75-80 \%$ of all cystic hygromas involve the neck and the lower portion of the face, 15-20\% occur in the axilla, while remaining $5 \%$ are found in the mediastinum, retropertoneum, abdominal viscera, groin , bones and scrotum. ${ }^{3}$

In this paper a case of axillary cystic hygroma confirmed at birth is discussed.

\section{Case}

A 32 year- old $\mathrm{G}_{3} \mathrm{P}_{2}$ was referred at 22 weeks of gestation for regular ultrasonography to rule out any congenital malformations.

Ultrasound evaluation revealed an alive single fetus(cephalic presentation, posterior/fundal placenta, normal amniotic fluid and biometry measurements were compatible with 23 weeks of gestation).Morphological evaluation of the fetus revealed a multiseptated cystic mass measuring 100x70x5 mm in the right axilla which had extended up to the right chest wall (Figure 1). The mass did not light up on colour Doppler examination and hence a diagnosis of axillary cystic hygroma was made. The right arm was extended over the mass and no other foetal anomalies were found.

The follow-up examination was done at 35 weeks, cystic mass increased moderately in size to $120 \times 90 \times 60 \mathrm{~mm}$. The mass had grown much less rapidly than the fetus.In view of the potential of having shoulder dystocia and obstructed labour, the baby was delivered by elective caesarean section at 38 weeks of gestation. The male infant weighting 2630 gram did not required any assistance at birth.He had APGAR score of 8 at $1 \mathrm{~min}$ and 10 at $5 \mathrm{~min}$.Clinically, he was noted to have a soft cystic, brilliantly transilluninant axillary mass measuring $15 \times 11 \mathrm{~cm}$ extending upto the right anterior chest wall ( Figure 2). No other anomalies were noted. The chest radiograph did not show any abnormality.

\section{Discussion}

Cystic hygroma is a congenital malformation of the lymphatic system that has its genesis in the lack of development of communication between the lymphatic and venous systems. ${ }^{4}$ There are at least three theories to explain the origin of cystic hygroma. The first theory ${ }^{5}$ suggests an early jugular - lymphatic obstructive hygroma. This obstruction impedes communication between the jugular lymphatic sacs and internal jugular vein. Other authors ${ }^{1}$ believe cystic hygroma is caused by an abnormal embryonic sequestration of lymphatic

\section{Correspondence}

Dr Narayan Bikram Thapa, MD

Department of Radiology, Kathmandu Model Hospital, Kathmandu, Nepal

Email:nadudocradio@yahoo.com 


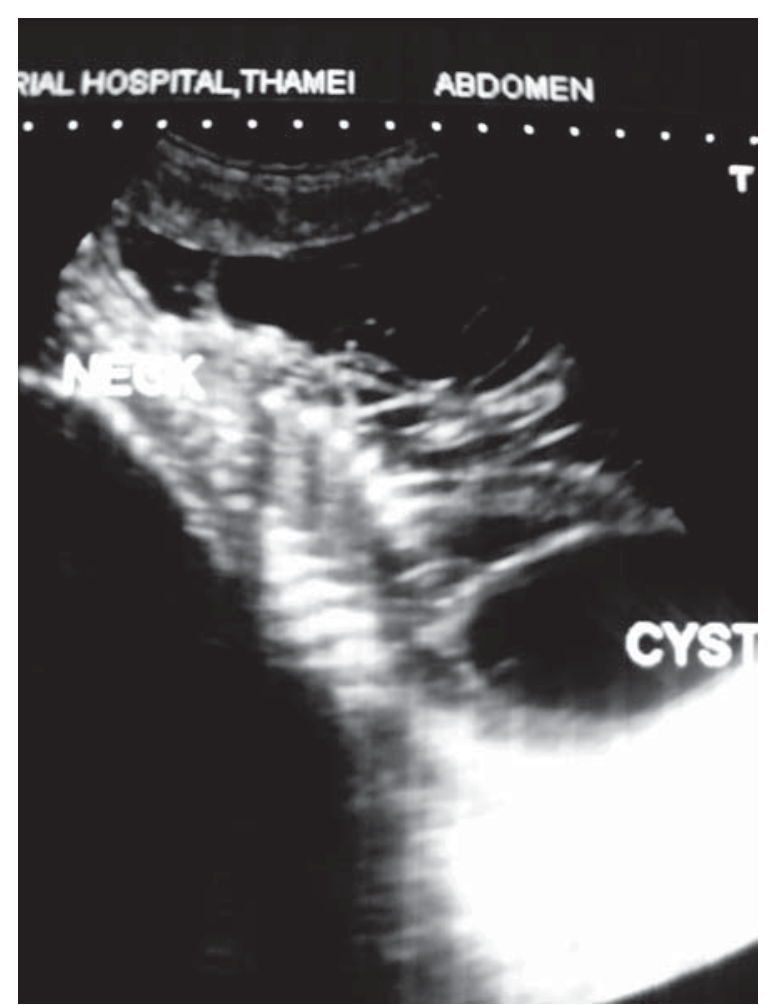

Fig. 1 Multilocular cystic mass in the right axilla extending to the chest wall.

tissue and its subsequent failure to join. A third theory ${ }^{6}$ suggests that abnormal budding of the lymphatics occurs between the sixth and ninth weeks of gestation.
These are then canalized. Of these three theories, the first seems the most likely. However other two theories could be applied to noncervical lymphangiomatosis.

Although the cystic hygroma may be isolated, in many cases it is associated with hydrops fetalis and chromosomal defects are found in more than $80 \%$ of the fetuses. ${ }^{6}$ Cystic hygromas may be associated with Turner syndrome, Noonan syndrome, trisomies and cardiac anomalies. ${ }^{7}$ Foetal axillary cystic hygromas have been reported rarely and usually as a sonographic finding in mid-gestation. ${ }^{9,10}$ On an ultrasonological scan it appears as a hypo-echoic multilocular cystic mass with septa of variable thickness. Scanning along the longitudinal axis of the humerus helps to identify the cystic mass easily. Unlike haemangioma, a cystic hygroma fails to light up on colour Doppler examination. Other differential diagnosis include high thoracic meningomyelocoele, and limb-body wall complex which is a complex mass of eviscerated organs.Considering its association with several chromosomal anomalies, determination of foetal karyotype may be undertaken for providing accurate diagnosis and genetic counseling. ${ }^{10}$ Sonological evaluation should also be undertaken for the detection of foetal skin oedema, ascites, pleural and pericardial effusions and cardiac or renal anomalies. Repeat sonological evaluations may be necessary for the evaluation of the tumour growth.As cystic hygromas are known to lead to obstructed labour, and neonatal asphyxia, an elective Caesarean section should be

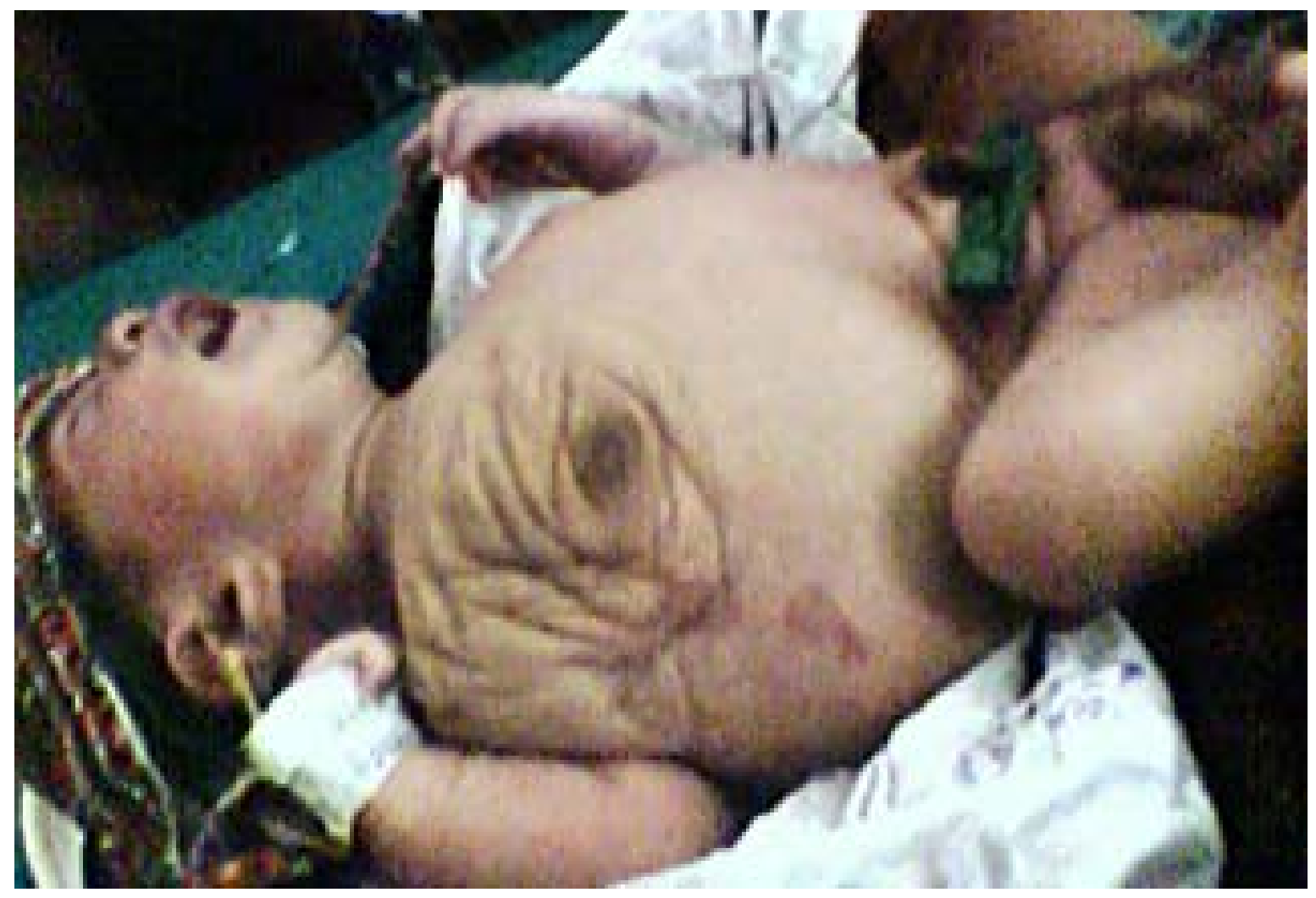

Fig 2. Soft cystic, brilliantly transilluninant axillary mass extending to the right anterior chest wall. 
considered as the preferred mode of delivery. These babies should be delivered at centers equipped to offer emergency neonatal ventilator. ${ }^{7}$

\section{Conclusion}

Cystic hygromas if diagnosed antenatally as a hypoechoic multilocular cystic mass with septation of variable thickness at anomaly scan may alert associated possibilities of triosomies and hydrops fetalis to direct obstetric interventions.

\section{References}

1. Goetsch E.Hygroma colli cysticum and hygroma axillare.Arch surg 1938;36:394-396.

2. Byrne J.,Blanc WA, Wartbuton D,et al. The significance of cystic hygroma in fetuses.Hum pathol 1984;15:61-67.

3. Eleni T,Philippe J. Cystic hygroma,advance course in fetal Medicine2003;07:10-11.

4. Panditt SK,Rattan KN,Budhiraja S,Solanki RS Cystic lymphangioma with special reference to rare sites.Indian J Pediatr 2000;67:339-41.

5. Vincenzo S,Alberto M, et al. Cystic hygroma, axillary, cervico-mediastinal.Advance course in Fetal medicine1992;03:13-21.

6. Pearce JM,Griffin D, Campbell S. Cystic hygroma in trisomy 18 and 21. Prenat Diagn1984;4: 317-375.

7. Manikoth P, Mangalore GP, Megha V. Axillary cystic hygroma.J Postgrad Med 2004;50(3):215216

8. Zanotti SD, LaRusso S, Coulson C. Prenatal sonographic diagnosis of axillary cystic lymphangiomas.J Clin Ultrasound 2001;29:112115

9. Reichler A, Bronshtein M. Early prenatal sonographic diagnosis of axillary cystic hygroma.J Ultrasound Med 1995;14:581-584

10. Ress A, Pijpers L,Schampers PT, Wladimiroff JW et al. The importance of chorionic villus sampling after first trimester diagnosis of cystic hygroma. Prenat Diagn1987;7:299-301 